\title{
Adult height is inversely associated with ischaemic stroke. The Caerphilly and Speedwell Collaborative Studies
}

\author{
Peter McCarron, Rosemary Greenwood, Shah Ebrahim, Peter Elwood, George Davey Smith
}

There is much interest in the association between exposures over the life course and risk of later disease. Attained adult height is determined by both genetic potential and growth in childhood. The latter is a useful marker of childhood circumstances, and consequently if associations between adult height and stroke are found they provide support for the hypothesis that exposures acting in childhood are important determinants of risk of stroke. Findings on this have been mixed although more recent studies have reported inverse associations for risk of stroke in men. ${ }^{12}$ A British study reported similar, although less impressive, associations. ${ }^{3}$ Only one of these studies could distinguish between ischaemic and haemorrhagic strokes, but adjustment for socioeconomic position-an important potential confounder-could not be made. ${ }^{1}$ We report on the association between attained height and risk of stroke in a representative sample of middle age British men.

\section{Methods and results}

From a representative population sample of 5368 men aged 45-59 years in South Wales and South West England 4861 (90.5\%), participated in a baseline survey in 1979-83. Detailed questionnaire and clinical examination data were collected. Height was measured using a Holtain stadiometer. Study subjects have been flagged on the National Health Service Central Register in Southport and this analysis is based on events from enrolment up to the end of 1997. Self reports of possible cerebrovascular events were supplemented by medical records, including postmortem reports. Strokes were classified as either ischaemic or haemorrhagic by two independent assessors using standard methods with all available clinical and pathological information (unpublished data).

Analyses were carried out using Cox's proportional hazards models.
Department of Social Medicine, University of Bristol, Canynge Hall, Whiteladies Road, Bristol, BS8 2PR

P McCarron

R Greenwood

$S$ Ebrahim

G Davey Smith

MRC Epidemiology Unit, Llandough

Hospital, Penarth, South Glamorgan

P Elwood

Correspondence to: Dr McCarron

Accepted for publication 29 September 1999
Table 1 Hazard ratios for height quartiles for each stroke subtype

\begin{tabular}{|c|c|c|c|c|c|}
\hline \multirow[b]{2}{*}{ Height (m) } & \multirow{2}{*}{$\begin{array}{l}\text { Number } \\
\text { of cases }\end{array}$} & \multicolumn{2}{|l|}{ Age adjusted } & \multicolumn{2}{|l|}{ Fully Adjusted* } \\
\hline & & $H R$ & $95 \% C I$ & $H R$ & $95 \% C I$ \\
\hline \multicolumn{6}{|l|}{ All strokes } \\
\hline$\leqslant 1.671$ & 96 & 1.00 & reference & 1.00 & reference \\
\hline $1.672-1.716$ & 63 & 0.67 & (0.49 to 0.93$)$ & 0.71 & (0.51 to 0.97 ) \\
\hline $1.717-1.759$ & 68 & 0.78 & (0.57 to 1.06$)$ & 0.84 & (0.61 to 1.15$)$ \\
\hline$\geqslant 1.760$ & 62 & 0.72 & $(0.52$ to 0.99$)$ & 0.79 & $(0.57$ to 1.09$)$ \\
\hline Hazard ratio (CI)per $10 \mathrm{~cm}$ increase in height & & $0.80(0.67,0.95)$ & & $0.84(0.71,1.01)$ & \\
\hline$p$ for trend & & 0.012 & & 0.060 & \\
\hline \multicolumn{6}{|l|}{ Ischaemic strokes } \\
\hline$\leqslant 1.671$ & 92 & 1.00 & reference & 1.00 & reference \\
\hline $1.672-1.716$ & 59 & 0.66 & (0.48 to 0.92$)$ & 0.69 & (0.50 to 0.96$)$ \\
\hline $1.717-1.759$ & 60 & 0.72 & (0.52 to 0.99$)$ & 0.77 & (0.56 to 1.07$)$ \\
\hline$\geqslant 1.760$ & 53 & 0.64 & (0.45 to 0.90$)$ & 0.70 & (0.50 to 0.99$)$ \\
\hline Hazard ratio (CI)per $10 \mathrm{~cm}$ increase in height & & $0.77(0.64,0.92)$ & & $0.82(0.68,0.98)$ & \\
\hline$p$ for trend & & 0.005 & & 0.030 & \\
\hline \multicolumn{6}{|l|}{ Fatal ischaemic strokes } \\
\hline$\leqslant 1.671$ & 23 & 1.00 & reference & 1.00 & reference \\
\hline $1.672-1.716$ & 14 & 0.63 & (0.32 to 1.22$)$ & 0.66 & $(0.34$ to 1.29$)$ \\
\hline $1.717-1.759$ & 6 & 0.29 & $(0.12$ to 0.71$)$ & 0.32 & (0.13 to 0.80$)$ \\
\hline$\geqslant 1.760$ & 8 & 0.39 & $(0.17$ to 0.88$)$ & 0.44 & (0.19 to 1.01$)$ \\
\hline Hazard ratio (CI)per $10 \mathrm{~cm}$ increase in height & & $0.54(0.35,0.82)$ & & $0.61(0.40,0.93)$ & \\
\hline$p$ for trend & & 0.003 & & 0.02 & \\
\hline \multicolumn{6}{|l|}{ Non-fatal ischaemic strokes } \\
\hline$\leqslant 1.671$ & 69 & 1.00 & reference & 1.00 & reference \\
\hline $1.672-1.716$ & 45 & 0.67 & (0.46 to 0.98$)$ & 0.70 & (0.48 to 1.03$)$ \\
\hline $1.717-1.759$ & 54 & 0.86 & (0.60 to 1.23$)$ & 0.92 & (0.64 to 1.32$)$ \\
\hline$\geqslant 1.760$ & 45 & 0.72 & (0.49 to 1.06$)$ & 0.79 & (0.53 to 1.16$)$ \\
\hline Hazard ratio $(C I)$ per $10 \mathrm{~cm}$ increase in height and & & $0.84(0.68,1.03)$ & & $0.88(0.72,1.08)$ & \\
\hline$p$ for trend & & 0.087 & & 0.23 & \\
\hline
\end{tabular}

^Adjusted for diastolic blood pressure, BMI, smoking, social class, total cholesterol, triglycerides, diabetes, angina. 
Full data were available for 4826 men of whom 287 had a stroke (264 ischaemic and 25 haemorrhagic). In univariate analyses men without stroke were taller than men with stroke $171.7 \mathrm{~cm}$ compared with. $170.3 \mathrm{~cm}(\mathrm{p}=$ 0.0003 ). In age adjusted analyses, height as a continuous variable, was inversely associated with risk of stroke- both ischaemic and haemorrhagic, and fatal and non-fatal. After adjusting for diastolic blood pressure, diabetes, angina, body mass index, social class, smoking, and cholesterol, there was mild attenuation of the associations, with the inverse associations for all stroke no longer attaining significance, but there were statistically significant inverse associations for ischaemic, and fatal ischaemic strokes (table 1). Smaller non-significant inverse associations were found for non-fatal ischaemic and haemorrhagic stroke (data not shown).

With height as a categorical variable subjects in the tallest quartile had a $30 \%$ and a more than $50 \%$ lower risk of ischaemic and fatal ischaemic stroke respectively compared with those in the shortest quartile (table 1). Trends were significant for all strokes, ischaemic strokes and fatal ischaemic strokes. The hazard ratios for haemorrhagic stroke were unstable as they were based on small numbers, and are not presented.

\section{Comment}

Our results show that tall men, as well having less risk of stroke, particularly ischaemic stroke, have a much reduced risk of a fatal ischaemic cerebrovascular event. The results are consistent with recently reported findings on all stroke subtypes combined. ${ }^{12}$ However, they contrast with a recent British study that found only a weak and non-significant inverse association. ${ }^{3}$ In that study the authors hypothesised that the lack of association was because height is more strongly related to reduced risk of haemorrhagic rather than ischaemic stroke, and the association was not apparent as data on stroke subtypes were not available. Although the Norwegian study did find such an association, data for both sexes were combined and adjustment for socioeconomic position was not possible. ${ }^{1}$ Our findings do not support this hypothesis.

We have shown previously that deprivation during childhood increased the risk of stroke mortality in adulthood, independent of later socioeconomic circumstances. ${ }^{4}$ Here we show that height is inversely associated with ischaemic stroke risk, and that other risk factors in adulthood and socioeconomic position do not explain this association. Fetal growth, early life socioenvironmental circumstances, infection and nutrition in childhood are related to adult height and thus may determine stroke risk. Trends in these early life factors may explain the downward secular trends in stroke mortality observed in many countries.

We thank Zoe Wilkins for secretarial support and Eileen Coleman, Janie Hughes, Janet Lloyd for their help with collection and management of the data.

$\mathrm{PMCC}$ assisted with data collection and data analyses and interpretation. RG managed the data and performed the analyses on the dataset. PE initiated the study and is a co-principal investigator. SE is a co-principal investigator on the study. GDS formulated the hypothesis. All authors contributed to writing the paper.

Funding: this research was funded by the NHS ExecutiveNorthern And Yorkshire NHS R\&D Programme On Cardiovascular Disease And Stroke.

Conflicts of interest: none.

1 Njolstad I, Arnesen E, Lund-Larsen PG. Body height, cardiovascular risk factors, and risk of stroke in middleged men and women. A 14-year follow-up of the Finnmark Study. Circulation 1996;94:2877-82.

2 Parker DR, Lapane KL, Lasater TM, et al. Short stature and cardiovascular disease among men and women from two southeastern New England communities. Int 7 Epidemiol 1998;27:970-5.

3 Wannamethee SG, Shaper AG, Whincup PH, et al. Adult height, stroke, and coronary heart disease. Am $\mathcal{F}$ Epidemiol 1998; 148:1069-76.

4 Davey Smith G, Hart C, Blane D, et al. Adverse socioeconomic conditions in childhood and cause-specific adult mortality: prospective observational study. BMF 1998;316:1631-5. 